\title{
Prática pedagógica no processo de ensino de Biologia dos professores do Colégio Estadual de Brumado (Bahia)
}

\author{
Pedagogical practice in the teaching processo $f$ Biology of the teachers of the \\ State College of Brumado-Bahia (Brazil)
}

\author{
PORTO, Carlos Renan de Souza. Especialista/Licenciado em Ciências Biológicas \\ Universidade Federal do Vale do São Francisco - UNIVASF. Av. José de Sá Maniçoba, S/N - Petrolina - PE - Brasil. \\ CEP: 56.304-917 / Telefone: (87) 2101-6823 / E-mail: carlosrenan_bdo@hotmail.com
}

CAVALCANTE, Kellison Lima Cavalcante. Mestre/Licenciado em Ciências Biológicas

Instituto Federal de Educação, Ciência e Tecnologia do Sertão Pernambucano - Campus Petrolina. Rua Maria Luiza de Araújo Gomes Cabral, S/N, João de Deus - Petrolina - Pernambuco - Brasil. CEP: 56.316-686 / Telefone: (87) 2101-4300/ E-mail: kellison.cavalcante@ifsertao-pe.edu.br.

\section{RESUMO}

A prática pedagógica no ensino de biologia deve ocorrer de modo que os alunos possam compreendê-la e visualizá-la na vida cotidiana, despertando nele o interesse por esta área de conhecimento. 0 presente estudo tem por objetivo analisar essa prática pedagógica no ensino de biologia dos professores do Colégio Estadual de Brumado-CEB, no município de Brumado-Bahia, onde foram observados dados importantes com o uso de diário de bordo para registro, que tinha a finalidade de observar e de relatar a prática docente no ensino de Biologia, bem como o processo de aprendizagem. Em nossa pesquisa, foram percebidos o envolvimento e a procura dos docentes na constante busca pelo aperfeiçoamento de sua formação e o desenvolvimento da aprendizagem dos estudantes, o que nos fez observar as estratégias utilizadas, os instrumentos, as metodologias, bem como as dificuldades e as limitações, em todo o processo de ensino-aprendizagem. Identificamos que os professores utilizam as novas tecnologias como recursos didáticos, para melhor fixação dos conteúdos de biologia, tido como muitos uma disciplina difícil, com muitos termos científicos, e com a utilização de tais recursos se torna uma aula mais dinâmica e contribui de forma significativa no processo de aprendizagem. Portanto, é necessária uma boa prática no ensino de biologia para que os docentes despertem nos discentes a ação investigativa da pesquisa durante seu processo formativo, desenvolvendo competências e habilidades de forma contextualizada na construção dos saberes.

Palavras-chave: Prática Docente; Ciências Biológicas; Aprendizagem.

\begin{abstract}
Pedagogical practice in the teaching of biology must occur so that students can understand and visualize it in everyday life, awakening their interest in this area of knowledge. The present study aims to analyze this pedagogical practice in the teaching of biology of teachers at the Colégio Estadual de Brumado-CEB, in the municipality of Brumado-Bahia (Brazil), where important data were observed with the use of a logbook for registration, which was intended to to observe and report the teaching practice in the teaching of Biology, as well as the learning process. In our research, we were perceived involvement and demand of teachers in the constant search for improvement of their training and the development of student learning, which made us to observe the strategies used, tools, methodologies, as well as the difficulties and limitations in all teachinglearning process. We identified that teachers use new technologies as didactic resources, for better fixation of biology contents, with many a difficult discipline, with many scientific terms, and with the use of such resources it becomes a more dynamic class and contributes significantly in the learning process. Therefore, good practice in teaching biology is necessary for teachers to awaken in their students the investigative action of research during their formative process, developing skills and abilities in a contextualized way in the construction of knowledge.
\end{abstract}

Keywords: Teaching Practice; Biological Sciences; Learning. 
PORTO, C. R. S.; CAVALCANTE, K. L. (2020)

Prática pedagógica no processo de ensino de Biologia dos professores do Colégio Estadual de Brumado (Bahia)

\section{Introdução}

Gouvêa (2006) defende que o principal papel da escola é dotar as pessoas de condições teóricas e práticas para que elas utilizem, transformem e compreendam o mundo da forma mais responsável possível. Nesse sentido, de acordo com Rodrigues (2008), os conteúdos são as grandes alavancas desse processo, pois além dos conteúdos conceituais (saber sobre), o currículo é formado pelos conteúdos procedimentais (saber fazer) e os atitudinais (o ser) e, a partir dessas três dimensões, é que o professor deve nortear a sua prática.

Para obter bons resultados no processo de ensino-aprendizagem, o professor deve conhecer a metodologia que mais se ajusta à sua prática pedagógica, utilizando-a na busca de conhecimento e aprimoramento em sala de aula, o que, de acordo com Moreira (2004), deve ser uma atividade concreta, com resultados comprovados, e de fundamental importância no processo de ensinoaprendizagem, pois ela está ligada diretamente às atividades desenvolvidas pelos alunos sob a direção do professor, visando sempre suas habilidades, seus hábitos e suas atitudes, além de suas capacidades intelectuais, atentando para a prática que o professor adota, influenciando diretamente na aprendizagem dos alunos e na opinião deles acerca da Biologia, considerada como uma área de conhecimento complexa, com nomes "estranhos". Vale ressaltar que é de suma importância o professor ser um incentivador da inteligência coletiva, e não apenas mero transmissor de conteúdo (LEITE, 2015, p. 50).

É essencial, portanto, que o docente tenha uma boa prática pedagógica, a fim de que possa auxiliar no processo de ensino-aprendizagem do aluno, estimulando nele o desejo e o gosto pelo estudo, ao criar situações que instigue o indivíduo a pensar, a analisar e a relacionar os aspectos e conteúdos estudados com a realidade em que vive, havendo também uma adequação de linguagem pelo professor com relação as nomenclaturas e ou vocábulos comuns às ciências biológicas pouco usuais no dia-a-dia, construindo uma ressignificação dos conceitos e práticas no ensinoaprendizagem de biologia, fazendo-se importante, também, que o docente faça uma autoavaliação e da leitura crítica da profissão, atrelada às realidades sociais como ponto de partida para a modificação de referenciais, o que corrobora com a tese de Pimenta (1996). Diante desta explanação, o presente trabalho tem por objetivo analisar a prática pedagógica dos professores de biologia do Colégio Estadual de Brumado, bem como suas competências frente aos conteúdos dos componentes curriculares que lecionam, o que caminhará em consonância com o interesse de se conhecer como ocorre a prática pedagógica no ensino de biologia em uma escola, bem como a dinâmica nesse processo de ensino-aprendizagem.

\section{A Prática Pedagógica}

A prática pedagógica ressalta a característica do professor reflexivo, que deve orientar o aluno na redescoberta do conhecimento e na aplicação no seu cotidiano. Assim, um planejamento que obtenha êxito em todas as suas etapas terá como resultado uma participação efetiva na aprendizagem dos conteúdos curriculares propostos para a disciplina. Ter uma boa prática em sala 
PORTO, C. R. S.; CAVALCANTE, K. L. (2020)

Prática pedagógica no processo de ensino de Biologia dos professores do Colégio Estadual de Brumado (Bahia)

garante ao professor um bom desenvolvimento e uma aprendizagem por parte dos alunos, sendo necessário que o docente esteja sempre atento às novas tecnologias e inovações no ensino de biologia, conforme enfatiza Souza et.al (2016):

Com o grande avanço na área da educação e com avanços de pesquisas e modernização de informações em tempo real, o ensino de biologia precisa de estratégias na construção de ensino e aprendizagem que compreenda o jeito e métodos dos maios diversos espaços de conhecimentos, já que vivemos em uma era tecnológica (SOUZA et.al, 2016, p.26 ).

Desta forma, é necessário que o professor tenha uma boa formação, entendida, conforme Mello (1999), como um processo em constante construção, de forma inicial e continuada, que deve sempre estar voltada aos desafios do cotidiano em sala de aula, acompanhada, também, do avanço tecnológico. Corroborando com esta tese, ao mesmo tempo em que a complementa, Ferreira (2014), essa formação também pode acontecer através de trocas de experiências entre colegas de profissão, em atividades que são realizadas em sala, na escola, nos eventos e projetos pedagógicos, propostas, etc. Assim, quanto mais interdisciplinar for o trabalho da equipe de uma determinada instituição, melhores resultados teremos em favor de sua comunidade discente. $\mathrm{E}$ com isso, a prática docente ampara o exercício do professor, envolvendo, inclusive, o aprimoramento profissional do docente:

É notório também que através de uma boa prática pedagógica trará muitos ensinamentos, lições e aprendizado, onde ela funcionará como uma "bússola", orientando-o em determinados momentos, além de dá suporte, auxiliando-o para que ele não desista de ser um subsídio para o educando, aonde o próprio professor possa recorrer e repensar sua prática no dia-adia. (FERREIRA, 2014, p.52).

Portanto, é essencial que o professor tenha uma boa “didática” na explanação dos conteúdos, atento à tríade (ação-reflexão-ação) enfatizada por Pimenta (2006) como essencial para que o conhecimento em sala seja efetivamente construído e reconstruído, entre alunos e professores, partindo do docente a preocupação sobre o que ensinar, como ensinar e para que ensinar. Vale ressaltar ainda, que o docente tem que partir sempre de questionamentos, permitindo a participação dos alunos em metodologias ativas, ressignificando assim os temas abordados na aula, a fim de que eles compreendam a metodologia aplicada, e possam contribuir de forma significativa no processo de ensino-aprendizagem. As aulas práticas são de extrema importância e no que diz respeito ao ensino de biologia, ela dá um suporte a mais para o professor trabalhar com os alunos. Sobre isto, Leite (2014) destaca:

É notório que a inserção de experimentos e demonstrações em sala de aula, representa uma ótima ferramenta para uma melhor assimilação dos conteúdos que está sendo trabalho em sala, estabelecendo uma relação dinâmica entre teoria e prática, possibilitando uma visão mais ampla e crítica dos conteúdos. (LEITE, 2014, p.20).

Partindo deste pressuposto, Leite (2014) enfatiza que estas práticas, quando bem aplicadas 
PORTO, C. R. S.; CAVALCANTE, K. L. (2020)

Prática pedagógica no processo de ensino de Biologia dos professores do Colégio Estadual de Brumado (Bahia)

e desenvolvidas, podem auxiliar tanto os alunos quanto os professores na tarefa de ensinar e aprender, pois, através destes mecanismos, o aluno passa a ter uma visão cientifica mais real. Além disso, possibilitará ao educando uma melhoria na qualidade de ensino, bem como ajuda no desenvolvimento da capacidade de observação e reflexão dos alunos. Neste sentido, Capelleto (1992) em relação às aulas práticas aliada aos conteúdos, esclarece que:

As aulas práticas podem funcionar como um contrapondo das aulas teóricas, como um poderoso catalisador no processo de aquisição de novos conhecimentos, pois a vivência de uma certa experiência facilita a fixação do conteúdo a ela relacionado, descartando-se a ideia de que as atividades experimentais devem servir somente para a ilustração da teoria (CAPELLETO, 1992, p.224).

É imprescindível que o aluno raciocine e realize as mais diversas etapas da investigação que uma aula prática propõe, o que, segundo Capelleto (1992), vai ao encontro da problematização dos conteúdos trabalhados em sala, sendo essencial para que os alunos sejam guiados em suas observações, ao mesmo tempo em que, ao ouvir os alunos, haverá um redimensionamento do olhar de todos sobre o objeto de estudo. Ao refletir sobre o ensino-aprendizagem nas ciências biológicas, Krasilchik (2008) destaca a importância das aulas em laboratório, tendo em vista que no ambiente laboratorial o aluno terá um maior contato com os fenômenos, manipulando os materiais e equipamentos, ao mesmo tempo em que observará os micro-organismos. Dessa forma, somente nas aulas práticas é que os alunos enfrentam os resultados não previstos, cuja interpretação desafia a imaginação e raciocínio de cada um. Portanto, é notório que as aulas práticas, além de ajudar no desenvolvimento do processo de ensino e aprendizagem, facilitam na compreensão dos conteúdos pelos alunos tornando-a mais dinâmica, transformando o ambiente escolar mais atrativo, além de desenvolver o aprendizado e o respeito à natureza, à ciência e à tecnologia, assim como sobre os principais conceitos e princípios científicos, adquirindo com isso habilidades manipulativas e cognitivas, ao passo em que pode desenvolver interesses, atitudes e valores que ajudarão o corpo discente no processo de aprendizagem (CAMPOS; NIGRO, 2009; MORAES; ANDRADE, 2010).

\section{Material e métodos}

O estudo foi realizado no Colégio Estadual de Brumado-CEB (Figura 1), localizado no município de Brumado-Bahia. No referido colégio, são ofertadas as três séries do ensino médio regular ( $1^{\circ}$ ano, $2^{\circ}$ ano e $3^{\circ}$ ano) (diurno e noturno), Educação de Jovens e Adultos-EJA (vespertino e noturno) e Educação especial (diurno e noturno), integrada ao ensino regular, além de atender alunos das zonas urbana e rural. A escola possui uma estrutura ampla e arborizada, com pátios ao ar livre, 23 salas de aula com ventiladores dispostos em três pavilhões (o terceiro pavilhão é um prédio com primeiro andar), nove sanitários, sala dos professores, laboratório de informática, laboratório de química, rádio estudantil, sala de recursos multifuncionais para Atendimento Educacional Especializado (AEE), biblioteca, almoxarifado, cozinhas, auditório, secretaria, direção e quadra poliesportiva. A rotina escolar é caracterizada pela alternância de salas feitas pelos alunos, 
PORTO, C. R. S.; CAVALCANTE, K. L. (2020)

Prática pedagógica no processo de ensino de Biologia dos professores do Colégio Estadual de Brumado (Bahia)

enquanto o professor permanece na sala fixa, os alunos se deslocam durante o tocar da sirene nas mudanças de horário das diferentes disciplinas.

Figura 1: Colégio Estadual de Brumado (Brumado-Bahia): (a) entrada; (b) espaço interno

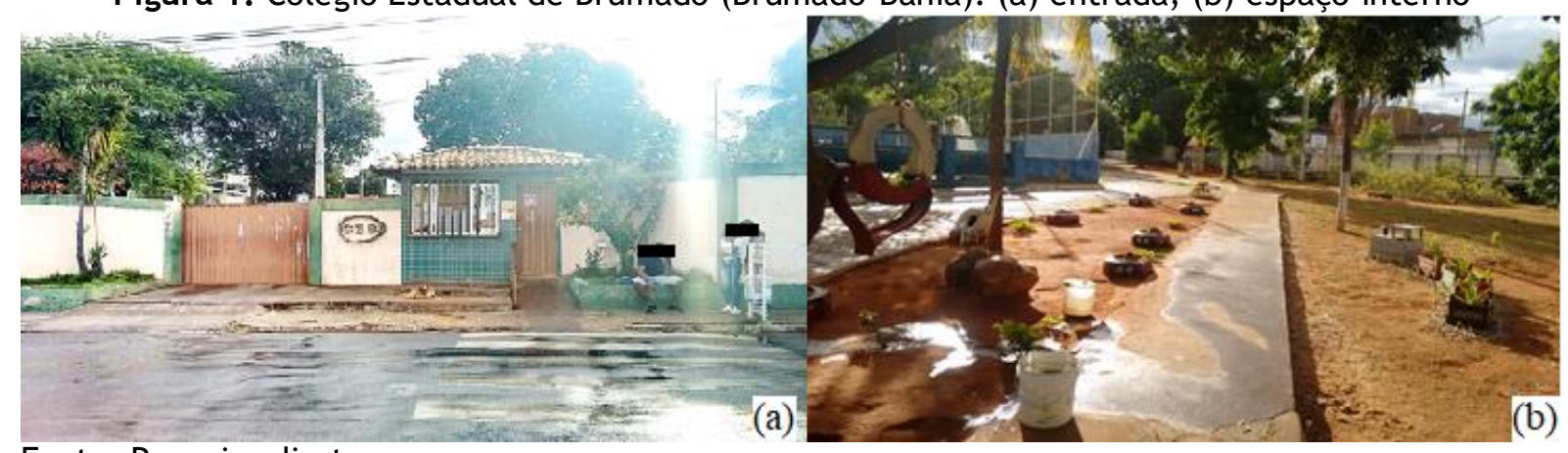

Fonte: Pesquisa direta

Para a realização desse trabalho foi feito um estudo de observação no Colégio Estadual de Brumado, no período entre 18 a 25 de fevereiro de 2020, com o uso de diário de bordo para registro dos dados observados e estruturados, com a finalidade de observar e relatar a prática docente no ensino de Biologia e o fortalecimento e desenvolvimento do processo de ensino-aprendizagem, a fim de obter as informações necessárias para a pesquisa. Sendo esta uma pesquisa do tipo observacional, em conformidade com o que defende Gil (2008), é importante esclarecer que a observação nada mais é que o uso dos sentidos com vistas a adquirir os conhecimentos necessários para o cotidiano, reservando ao observador o papel importante na coleta, na análise e na interpretação dos dados.

0 delineamento da pesquisa foi realizado através de um estudo de campo, sendo enfatizado por Gil (2008) como uma pesquisa que implicará em estudos de apenas um único grupo ou comunidades relacionados, bem como a interação de seus componentes, nesse caso, a prática adotada pelos professores no ensino de biologia. Assim, o processo de observação foi estruturado em seis eixos de análise, para compreensão da prática docente no ensino de Biologia, conforme Quadro 1.

Quadro 1 - Análise da prática docente no ensino de Biologia no Colégio Estadual de Brumado (Bahia)

$$
\text { EIXO }
$$

\section{OBJETIVO}

\begin{tabular}{cc}
\hline Estratégias de ensino & $\begin{array}{c}\text { Identificar os recursos utilizados nas estratégias de } \\
\text { ensino para melhorar o processo de ensino- } \\
\text { aprendizagem }\end{array}$ \\
\hline Formas de disseminação dos conteúdos & $\begin{array}{c}\text { Relacionar os processos de disseminação dos con- } \\
\text { teúdos de Biologia }\end{array}$ \\
Relacionamento professor-aluno & $\begin{array}{c}\text { Avaliar como ocorrem as formas de relacionamen- } \\
\text { to entre professores e alunos e suas relações no } \\
\text { processo de ensino-aprendizagem }\end{array}$ \\
Desafios na prática docente & $\begin{array}{c}\text { Descrever os principais desafios observados na } \\
\text { prática docente no ensino de Biologia }\end{array}$ \\
Metodologias aplicadas nas aulas & $\begin{array}{c}\text { Identificar metodologias que proporcionam a me- } \\
\text { lhoria na prática docente e que contribuem para o } \\
\text { fortalecimento da aprendizagem }\end{array}$ \\
\hline Limitações no ensino de Biologia & $\begin{array}{c}\text { Refletir sobre as barreiras observadas no ensino de } \\
\text { Biologia e o fortalecimento de práticas exitosas }\end{array}$ \\
\hline
\end{tabular}

Fonte: Elaborado pelos autores. 
PORTO, C. R. S.; CAVALCANTE, K. L. (2020)

Prática pedagógica no processo de ensino de Biologia dos professores do Colégio Estadual de Brumado (Bahia)

\section{Resultados e discussão}

"O ensino de Biologia objetiva que, além de o aluno compreender os conceitos básicos da disciplina, seja capaz de pensar independentemente, adquirir e avaliar informações, aplicando seus conhecimentos na vida diária" (KRASILCHIK, 2008, p. 89). Assim, o professor, aliado à prática pedagógica, cria procedimentos que possibilitam aos educando um olhar mais crítico através da construção de novas formas de aprender e de conhecer, obtendo-se, por fim a sensibilização e a conscientização entre ele e todo o processo de ensino.

Através da observação dos eixos de análise da prática docente no ensino de Biologia, percebemos o envolvimento e a procura dos docentes na constante busca pelo aperfeiçoamento e pelo desenvolvimento da aprendizagem dos estudantes. Assim, buscamos compreender as estratégias utilizadas, os instrumentos, as metodologias, bem como as dificuldades e as limitações. Ao observarmos as estratégias de ensino, identificamos a utilização de recursos audiovisuais, aulas práticas e realização de sondagens para contextualizar o conteúdo estudado em sala com a realidade do aluno. Seixas, Calabró e Souza (2017) enfatizaram a utilização das tecnologias educacionais além do livro didático, tais como: laboratório de informática, sala de vídeo, acesso à internet, datashow, laboratório de ciências, mídias, lousa digital, notebook, TV, DVD, vídeos, entre outros recursos metodológicos, auxiliam o professor na hora de ensinar os conteúdos, além de contribuir para uma alfabetização científica e tecnológica, sendo que essas aulas também possam envolver exposições teóricas, registros dos alunos e confrontações de ideias na construção de conceitos.

Em relação aos conteúdos de biologia, foi observado que ocorre a utilização de debates de temas relacionados à disciplina, aulas explicativas, com esquemas no quadro, a utilização de vídeos, além da utilização de aulas práticas ou experienciais. Deste modo, os conteúdos de biologia podem influenciar diretamente na aprendizagem dos alunos, pois muitos consideram esta área de conhecimento, repleta de nomenclaturas difíceis, termos científicos, e, se não for trabalhado de maneira contextualizada com a realidade dos alunos, acabam distanciando e criando uma "raiva" pela matéria. Gasparin (2014), em seus estudos, enfatiza que no processo ensino-aprendizagem, por intermédio do professor e da turma em si, haja uma abordagem tanto da teoria quanto da prática, sendo que a teoria surgirá como representação da prática, que é a base que possibilita o "fazer", e a prática em sala é que de fato transformará a realidade.

A partir deste pressuposto, Castoldi (2009) percebeu que, com a utilização de novos recursos didático-pedagógicos, irá ocorrer um preenchimento de lacunas do ensino tradicional, através da exposição de conteúdos de uma forma "diferenciada", tornando os alunos participantes ativos no processo de aprendizagem. É o que destaca também Leite (2014), classificando como de suma importância a integração das TICs ao processo pedagógico, contribuindo para um melhor enriquecimento e desenvolvimento no processo educacional, promovendo aos professores e aos alunos uma nova experiência de ensino-aprendizagem, podendo ainda utilizar-se de ambientes virtuais, considerados como enormes campos de pesquisa e apoio para o educador, para auxiliá-lo no aperfeiçoamento de sua didática. 
PORTO, C. R. S.; CAVALCANTE, K. L. (2020)

Prática pedagógica no processo de ensino de Biologia dos professores do Colégio Estadual de Brumado (Bahia)

Ao observamos a relação entre professor e aluno, identificamos que há sempre espaços para diálogos e ideias, colaboração, e que todos podem participar em sala de aula. Desse modo, Ferreira (2014) elencou em sua pesquisa que uma boa relação estes sujeitos, além de proporcionar uma política da boa convivência, pode trazer uma característica de "liberdade" em que ambos possam reconhecer seus valores, bem como sua importância durante todo o processo educativo, considerando e compartilhando os desafios e os limites na sala de aula, onde cada um possa, de forma direta ou indiretamente, dividir suas experiências nesse processo do conhecimento.

Em relação às dificuldades encontradas na prática do ensino de biologia, foram observados que os problemas mais comumente encontrados foram: 1)aluno sem a base de aprendizagem necessária para a apropriação do conhecimento discutido e apresentado em sala de aula, com muita dificuldade de compreensão; 2) falta de recursos para aulas práticas e de aparelhos multimídias (datashow); 3) dificuldade no nível de reflexão e sistematização dos conhecimentos; 4) domínio de leitura e interpretação; 5) desinteresse em desenvolver a autonomia intelectual; e 6) escassez de recursos audiovisuais e a limitação de materiais didáticos, ferramentas de suma importância no ensino de biologia.

Ferreira (2014), ao refletir sobre a prática pedagógica no ensino de biologia de uma escola pública do ensino fundamental e de ensino médio da rede estadual do município de Belém-PB, percebeu os seguintes desafios enfrentados pelos docentes, tais como: 1) carga horária insuficiente - sendo três aulas semanais, impossibilitando de trabalhar certos tipos de conteúdos; 2) número excessivo de alunos por turma; 3) falta de estrutura dos laboratórios existentes na escola, o que reflete no andamento de aulas práticas; e 4) falta de recursos multimídias, audiovisuais, para se trabalhar em sala, visto que há uma precariedade em questão à quantidade, assim como foi observado no Colégio estadual de Brumado.

É importante dizer que os problemas elencados coadunam com os mesmos vivenciados na nossa pesquisa, no Colégio Estadual de Brumado, Bahia, uma vez que, ao serem observadas as limitações no ensino de biologia do referido colégio, identificamos que o que mais desestimula no momento educacional atual é o desinteresses dos discentes, a falta de recursos e de ambiente adequado e muitos outros quesitos que "travam" o ensino-aprendizagem. Outro fator limitante observado foi em relação ao número de aulas (2 aulas semanais), sendo insuficientes para apresentar e discutir conteúdos tão extensos, além de existir a dificuldade dos alunos em visualizar e compreender determinados assuntos, que necessitam de recursos visuais para serem melhor compreendido, fatores estes já apontados por Rossasi e Polinarski (2011) em seu trabalho sobre as dificuldades/limitações encontradas na prática docente. Além disso, foi percebido que há uma falta de cuidados e de manutenção necessárias aos laboratórios encontrados nas escolas, associados à falta de domínio dos docentes em utilizar o laboratório como uma "ferramenta", que sem dúvidas, favorecerá para uma melhor aprendizagem.

A respeito das metodologias aplicadas nas aulas biologia, identificamos que não há a adoção de uma vertente específica, o que permite àquela comunidade um leque de opções a partir do que é oferecido a ela, adaptado ao tipo de público/espaço, de acordo com o nível de aprendizado, percebemos também que as aulas participativas, ilustradas ou práticas são eficazes para um bom 
PORTO, C. R. S.; CAVALCANTE, K. L. (2020)

Prática pedagógica no processo de ensino de Biologia dos professores do Colégio Estadual de Brumado (Bahia)

andamento das aulas. Foram observados também que os professores trabalham muito com aulas expositivas, realização de exercícios, apresentação de slides, confecção de murais, trabalhos em grupo, exibição de filmes, contribuindo de forma significativa para o aprendizado dos alunos, tornando assim, o conteúdo mais claro e fácil de ser compreendido, corroborando com que Lima e Garcia (2011) destacaram em sua pesquisa, classificando este tipo de abordagem como inerente às práticas facilitadoras e complementares à aprendizagem, passiveis de observações e experimentações, devidamente experenciadas e compartilhadas, constituindo, assim, as metodologias ativas para o aprimoramento do processo de ensino-aprendizagem, resultando numa verdadeira aprendizagem, categorizada pela construção de uma visão crítica, e ampla da Biologia, unificando a teoria à prática e à visualização destes conhecimentos no cotidiano.

É importante dizer que foi constatado que os equipamentos audiovisuais são um dos recursos didáticos mais utilizados, os quais são considerados aliados importantes na construção do conhecimento, tornando o processo educativo mais atraente e dinâmico. Observa-se, no entanto que muitos professores ainda encontram dificuldades de tomar para si tais recursos como parte integrante da sua comunicação. Entretanto, é bom ressaltar novamente que a utilização mais efetiva de recursos audiovisuais depende não só de atitude do professor, mas de um aparato de equipamentos em condições de uso, de organização na captação e na estocagem de CDs, DVDs, slides, revistas, cartazes, bem como de pessoal de apoio para uso e manutenção.

Vale ressaltar também, que mediante as transformações e avanços no âmbito escolar é de extrema importância que os professores estejam em constante observação e atualização das inovações trazidas para dentro das escolas. Nesse sentido, atualmente as escolas são um grande palco de transformações inovadoras, sejam elas de caráter pedagógicos ou tecnológicos que auxiliarão no processo de ensino-aprendizagem. Dessa forma, cabe ao docente sempre estar em cursos de formação que os permitirão no desenvolvimento do uso desses recursos tecnológicos, pois permitirão mudanças na ação pedagógica, ressignificadas por meio do processo de ação-reflexãoação, seus valores, além de adquirir subsídios para uma maior estruturação de aulas para seus alunos. (GUIMARÃES; BERNARDI, 2014, p.2). Assim, a prática pedagógica do docente precisa estar sempre em atualização, buscando aproximar cada vez mais o aluno com o processo de ensinoaprendizagem.

Assim, fica difícil imaginar esse processo de ensino e aprendizagem sem desenvolver a parte tecnológica com seus recursos e tudo que eles podem contribuir para enriquecer a prática pedagógica e torná-la mais atrativa e prazerosa. Isso faz com que nós, enquanto docentes, sintamos a necessidade de imergir no mundo tecnológico, nas inovações e nos avanços, em favor do ensino de Biologia, através dos seus recursos, para que haja sempre uma diversificação e uma implementação de novas metodologias, oferecendo aos alunos diferentes maneiras de se apropriar do conhecimento científico, uma vez que temos na escola um ambiente heterogêneo.

\section{Conclusões}

Diante da pesquisa realizada, pode-se observar um maior aprimoramento no perfil dos 
PORTO, C. R. S.; CAVALCANTE, K. L. (2020)

Prática pedagógica no processo de ensino de Biologia dos professores do Colégio Estadual de Brumado (Bahia)

professores de biologia, os quais apresentam um espírito inovador em sua prática docente, procurando trabalhar com estratégias de ensino que estimulem o aprendizado discente, no intuito de fugir do engessamento contido no método tradicional, comportamento utilizado pela maioria dos docentes da referida escola, os quais buscam desvincular o ensino a uma didática baseada apenas no livro didático e do quadro branco, inserindo sempre as aulas práticas e a utilização de recursos audiovisuais. Entretanto, a forma pouco usual de aulas práticas pela maioria dos professores ainda precisa ser discutida e pode provocar a aversão e o desinteresse por parte de alguns alunos, havendo, também, a necessidade de promover um maior envolvimento entre os docentes através do intercâmbio de saberes e a abordagem transdisciplinar, além de discussões de estratégias de ensino que influem no rendimento escolar dos alunos, ao exercitar, também a troca de experiências que norteiam o enfrentamento de desafios pertinentes ao ensino de biologia e métodos facilitadores da compreensão em sala de aula, corroborando com que defende Freire (1996, p. 90): "a ação docente é a base de uma boa formação escolar e contribui para a construção de uma sociedade pensante".

Portanto, é de extrema importância que o professor de biologia esteja atento aos novos avanços científicos e desperte nos discentes a ação investigativa da pesquisa durante seu processo formativo, desenvolvendo competências e habilidades de forma contextualizada na construção dos saberes dos educandos. Assim, Diniz-Pereira e Lacerda (2009) enfocam a prática da pesquisa como forma de "redimensionar a relação com a teoria e, finalmente, problematizar a relação entre sociedade e escola", além de contribuir de forma significativa no processo de ensino-aprendizagem, pois o trabalho pedagógico em sala de aula deve ser um componente essencial e fundamental, de forma efetiva no cotidiano escolar.

\section{Referências}

CAMPOS, M. C. da C.; NIGRO, R. G. Teoria e prática em ciências na escola: o ensino aprendizagem como investigação. 1. ed. São Paulo: FTD, 2009

CAPELETTO, A. Biologia e educação ambiental: roteiros de trabalho. Editora Ática, 1992.

CASTOLDI, R; POLINARSKI, C.A. A utilização de recursos didático-pedagógicos na motivação da aprendizagem. In: VII Simpósio Nacional De Ensino De Ciência E Tecnologia. Ponta Grossa, PR, 2009.

DINIZ-PEREIRA, J. E.; LACERDA, M. P. de. Possíveis significados da pesquisa na prática docente: ideias para fomentar o debate. Educação \& Sociedade. 2009, 30 (Septiembre-Diciembre). Disponivel em: <http://www.redalyc.org/articulo.oa?id=87313699015>. Acesso em 18. Mar. 2019.

FERREIRA, M. de C. A prática pedagógica no ensino de Biologia. [manuscrito]. Guarabira: UEPB, 2014.

GASPARIN, J. L. Semana pedagógica 2014: reflexões sobre o processo ensino-aprendizagem. 
PORTO, C. R. S.; CAVALCANTE, K. L. (2020)

Prática pedagógica no processo de ensino de Biologia dos professores do Colégio Estadual de Brumado (Bahia)

Disponível em: < https://www.youtube.com/watch?v=YbBxHS0Qfmc>. Acesso em 14. mar. 2019.

GIL, A. C. Métodos e técnicas de pesquisa social. 6. ed. São Paulo: Atlas, 2008.

GOUVÊA, G. R. R. Rumos da formação de professores para a educação ambiental. Educar em Revista, n. 27, p. 163-179, 2006.

GUIMARÃES, Carine Pistoia; BERNARDI, Giliane. A importância do uso das tecnologias na prática docente: os desafios e a necessidade da formação continuada,2014. Disponível em: < http://repositorio.ufsm.br/handle/1/11987>. Acesso em 01. Abr. 2019.

KRASILCHIK, M. Prática de ensino de Biologia. 4. ed. São Paulo: Editora da Universidade de São Paulo, 2008.

LEITE, B. da S. Tecnologias no ensino de Química: teoria e prática na formação docente. Curitiba: Appris. 2015.

LEITE, D. M. N. Práticas pedagógicas para o ensino de ciências. (Especialização em Ensino de Ciências). Universidade Tecnológica Federal do Paraná, Medianeira, 2014.

LIMA, D. B; GARCIA, R. N. Uma investigação sobre a importância das aulas práticas de Biologia no Ensino Médio. Cadernos do Aplicação, Porto Alegre, v. 24, n. 1, p. 201-224, 2011.

MELLO, L. de. Programas oficiais para a formação de professores. Revista Educação e Sociedade, Campinas: n. 68, 1999.

MORAIS, M. B.; ANDRADE, M. H. de P. Ciências: ensinar e aprender. 1. ed. Belo Horizonte: Dimensão, 2010.

MOREIRA, M. A. Teorias de aprendizagem. Porto Alegre: E.P.U. 2004.

PIMENTA, S. G. Formação de professores: identidade e saberes da docência. São Paulo, 2006.

RODRIGUES, L. D. Conhecimento e ressignificação: prática pedagógica em educação ambiental. Santa Cruz do Sul: EDUNISC, 2008.

ROSSASI, L. B.; POLINARSKI, C. A. Reflexões sobre metodologias para o ensino de biologia: uma perspectiva a partir da prática docente. Porto Alegre: Lume UFRGS, 2011.

SEIXAS, R. H. M.; CALABRÓ, L.; SOUSA, D. O. A Formação de professores e os desafios de ensinar Ciências. Revista Thema, v. 14, n. 1, p. 289-303, fev. 2017. Disponível em: 
PORTO, C. R. S.; CAVALCANTE, K. L. (2020)

Prática pedagógica no processo de ensino de Biologia dos professores do Colégio Estadual de Brumado (Bahia)

<http://revistathema.ifsul.edu.br/index.php/thema/article/view/413>. Acesso em: 12 mar. 2019.

SOUZA, T. T. de; MARCHI, M. I.; STROHSCHOEN, A. A. G. Professores de biologia e a busca por práticas pedagógicas voltadas ao letramento científico: uso de texto de divulgação científica. Caderno Pedagógico, Lajeado, v. 13, n. 1, p. 24-40, 2016. Disponível em < http://www.univates.br/revistas>. Acesso em 10 mar. 2019. 